The Lower Cretaceous flowering plants were contemporary and associated with members of the old Mesozoic flora, cycads, and so on, which were still predominant. In the Gault and Upper Cretaceous the angiosperms have gained the upper hand, and the vegetation assumes quite a modern character. Both monocotyledons and dicotyledons are present, in about the same proportions as in the living flora. Among the former, palms, reeds, and lilies, among the latter, willows, walnuts, beeches, oaks, planes, maples, breadfruits (found in Greenland), laurels, gum trees, ebonies, and dogbanes indicate some of the families represented. In fact the evidence shows that, from about the middle of the Cretaceous epoch, flowering plants were flourishing very much as they are now, so far, at least, as families or even genera are concerned.

We still have no clue to what Darwin called the "abominable mystery" of the sudden appearance of the higher plants. We have seen that they already existed, fully developed, in Lower Cretaceous times. It is interesting to inquire whether we have any earlier records. They are very scanty. Prof. Seward has described, from the Stonesfield Slate of Middle Jurassic age, simple, ovate leaves, like those of a dicotyledon. We cannot be certain; for there are ferns such as Drymoglossum with fronds somewhat similar, but dicotyledonous affinities are strongly suggested.

Much more important are Mr. Hamshaw Thomas's discoveries in the Lower Oolite of Yorkshire, a little older than the Stonesfield Slate. He has found fruits, ranged in two rows on a stalk, each fruit enclosing a number of seeds. Thus the structure was undoubtedly angiospermous in the literal sense, for the fruit was closed. Associated with these organs Mr. Thomas finds branched stamens, with four-lobed anthers like those of an angiosperm, and also compound palmate leaves. He gives good reasons for thinking that all these remains belonged together. It is evident that Mr. Thomas's fossils throw a new light on the early history of the angiosperms, though their relation to the main line of descent is still an open question.

The series of transformations we have briefly sketched is sufficiently striking. What has been called the succession of dynasties is, no doubt, the great feature in the past history of the kingdom of plants. We have, as yet, little to show by what means one dynasty succeeded another, or how the successive dominant races were related. That each new type arose much earlier than its full manifestation is obvious, and, as we have seen, there is often direct evidence of precursors in an age previous to the transformation of the flora. To unravel the course of descent in the transition, apparently so abrupt, from each flora to the next in succession, is at present a task beyond our powers ; we have attempted nothing more than to state the problem.

\title{
Photochemical Problems.
}

THE subject of photochemistry is one to which increasing attention is being given at the present time, as is exemplified by the large attendance and spirited controversies in the meeting, very international in character, held by the Faraday Society at Oxford on October $x$ and 2 . Whilst as a specialised field for the study of the action of light on chemical substances it is not without interest, in a broader sense it is the most important of all the sciences, for not only does it provide a common meeting-place for physicists, astronomers, and chemists, but, as the botanists have long observed and the medical profession is now realising, life is in great measure dependent on photochemical action.

In all photochemical reactions it is necessary to distinguish between what are termed primary and secondary processes. The first action of the light in producing chemical change is to undergo absorption by a molecule, thus converting it into an " activated " or "excited" molecule. According to the quantum theory all molecules excited or activated in this way become a distinct species characterised by a definite energy constant, which, in certain cases, is directly related to the frequency of the radiation absorbed by the relationship due to Stark and Einstein, $E=h_{v}$.

It is these activated molecules which are the reacting species in photochemical processes and, according to some investigators, notably Perrin, in thermochemical change also. If all reactions were simple, it is clear that for every quantum of light absorbed one molecule should enter into chemical reaction and we should obtain a very simple relationship between the amount of chemical action obtained and the number of light quanta absorbed. Closer consideration, however, indicates that this simple law may be but rarely fulfilled, for such an excited molecule may perform one of three possible operations. It may fluoresce and thus lose its newly acquired energy by the emission of radiation. Again, it may collide with another molecule, when one of two possibilities are open to it: on collision the internal energy may be liberated in the kinetic form, resulting in what is termed a supra elastic collision, or the internal energy may be handed on to the molecule it comes in contact with, this molecule then departing as an active molecule, a process termed photosensitisation. Finally, the possibility of chemical reaction on collision is presented. It is little wonder that in many reactions the photochemical efficiency is low.

In addition to such reactions there exists an everincreasing group in which the photochemical yield is much greater than is to be anticipated from consideration of the amount of light absorbed, or, one quantum apparently can cause several, in some cases tens of thousands of molecules to undergo reaction. Such reactions are now designated as "chain" reactions, and the various hypotheses as to their mode of action are at present a matter of heated controversy. One of the simplest explanations is that of the "atom" chain, which may be represented in operation in its simplest form by the following sequence of operations :
(I) $\mathrm{Cl}_{2}+h v \rightarrow \mathrm{Cl}_{2}^{\prime}$
(2) $\mathrm{Cl}_{2}{ }_{2}+\mathrm{H}_{2} \rightarrow \mathrm{HCl}+\mathrm{H}+\mathrm{Cl}$
(3) $\mathrm{H}+\mathrm{Cl}_{2} \rightarrow \mathrm{HCl}+\mathrm{Cl}$
(4) $\mathrm{Cl}+\mathrm{H}_{2} \rightarrow \mathrm{HCl}+\mathrm{H}$.

in which the primary photochemical process of activation (I) is followed by a series of steps $2,3,4$. It is clear that 3,4 represent two links in a chain which can only terminate when an atom is arrested in some manner. 
The great ingenuity required in devising probable chain mechanism for reactions, such as the photochemical decomposition of hydrogen peroxide or the chlorination of hydrocarbons of the aromatic series, has caused many to reject this conception, originally due to Nernst, and to substitute in its place one of the following hypotheses. According to the "hot molecule" theory of Christiansen and Kramers, the products of a reaction such as

$$
\mathrm{Cl}_{2}^{\prime}+\mathrm{H}_{2}=2 \mathrm{HCl}
$$

must contain not only the original energy of activation but also the energy liberated by the chemical reaction; they are thus more "active" than their neighbours. It is imagined that a "hot" molecule formed in this way may excite another reactant molecule on collision. Again, it may be imagined that this energy, instead of being contained in the products, may be liberated as radiation which is absorbed by the surrounding reactants activating them in turn; this conception has in fact been made even more concrete by the definite conception of a "quantum" chain.

More recently, due to the investigations of Frank and Cario, the scope of the methods of photosensitisation in which an excited molecule can, on collision with a reactant, hand on its energy of activation to it, thus causing subsequent chemical reaction, has been greatly extended by the employment of mercury vapour as sensitising agent. By such means the amount of energy capable of being conveyed in this manner is far greater than with the sensitising agents usually employed, such as molecules of the halogens or the dyes employed in the photographic plate. It is possible that the active nitrogen of Lord Rayleigh $(V=9.5$ volt) may prove an even more powerful conveyer of energy than mercury atoms excited with the line $\lambda_{2537}$. The ready production of atomic hydrogen in this manner has opened up a path by which the properties of the organic radicals, such as ethyl, formed by the reaction may be investigated.

$$
\mathrm{C}_{2} \mathrm{H}_{4}+\mathrm{H} \rightarrow \mathrm{C}_{2} \mathrm{H}_{5}
$$

Whilst these natural processes may be considered at the present time to be capable both of reasonably precise experimental investigation and their real existence capable of being demonstrated, the situation is quite otherwise in certain other, phenomena, an adequate explanation for which is as yet not forthcoming.

It is found that in certain reactions hitherto considered as extremely simple in character, such as the decomposition of ozone, the photochemical efficiency may remain unchanged even for low pressures of the reactant and sensitising agent, chlorine, whilst the presence of indifferent gases exerts a marked influence on the reactant velocity. According to the experiments of Wien, the life of an excited molecule is of the order of $\mathrm{ro}^{-7}$ seconds and metastable forms of active molecules are as yet unknown. Whatever the active species may be in this particular reaction, it is clear that it must have a relatively long life ; furthermore, it can suffer a number of collisions with indifferent gas molecules without losing its energy, this number varying with the nature of the gas. Various explanations, such as the existence of intermediate compounds, the restriction of the reaction to the walls of the vessel and replacing the concept of an excited molecule by an excited atom, have all been advanced on very slender foundation.

Finally, it would appear from consideration of the decomposition of nitrogen pentoxide at very low pressures, that the process of distribution of internal energy amongst these molecules can proceed at a rate much faster than is to be anticipated from the Maxwellian period of molecular relaxation. If, indeed, this process occurs through the agency of radiation, nitrogen pentoxide must be singularly opaque to its own selfgenerated radiation.

It may be anticipated that increased attention will be given to the subject of photochemistry, for it is clear that it opens a door to some of the most interesting and important fields in the region of atom dynamics, a subject on which, in the words of Goethe, we are anxious to have "more light."

ERIC K. RideAL.

\section{French Contributions to Metallurgy.}

THE well-known attention which has been devoted to the history of metallurgy by Sir Rohert Hadfield receives an interesting supplement in a paper recently read (Oct. 5) in Paris at a congress of industrial chemistry organised by the French Society of Chemical Industry. The main theme of the address is the interrelation of British and French research in metallurgy, but the aspect, which to most readers will be found of the greatest interest, is the excellent résumé given of the debt which this subject owes to French men of science. As an example, the author pays generous tribute to the importance, in connexion with his own discovery of manganese steel, of the investigations carried out by the Terre Noire Cie. on the commercial production of ferrous alloys very high in manganese.

The paper, which is characterised by the pleasing discursiveness associated with similar lectures which Sir Robert Hadfield has already delivered on metallurgical history, contains, however, nothing more interesting than the photo-micrograph, now published for the first time, of the structure of the iron of the famous Delhi pillar, to which the author has devoted considerable attention. To metallographers interested in the remarkable resistance of this pillar to corrosion this structure shown in Fig. I will be of more than passing interest. The almost complete freedom from slag throws more than a little doubt on the view that a large part in the resistance of wrought iron to corrosion, a fact still awaiting an adequate explanation, is played by inclusions of slag.

The account given of French contributions to metallurgy since the time of Réaumur (I722) is of considerable interest. In the $5^{\circ}$ years which followed, there appeared a number of important metallurgical books in France, of which the titles of 27 are recorded. A brief account is given of the more important contributions to metallurgical knowledge during this period. Among the older names one meets those of Réaumur himself, Berthollet, Vauquelin, the discoverer of chromium, the metal which rendered the production of a rustless steel a possibility, of Berthier

NO. 2922 , VOL. I I 67 